\title{
Climate change and local awareness: a comparative study on tourism stakeholders in Zandvoort (NL) and Costa del Sol (ES)
}

\author{
R. Gaita \& M. Both \\ Leisure Tourism \& Environment MSc, Wageningen University, \\ The Netherlands
}

\begin{abstract}
This paper presents and discusses the findings of two researches that investigate the translation of the global debate on tourism and climate change into the discourses of different categories of local tourist stakeholders (policymakers, private entrepreneurship and NGO) in order to assess the respective perceptions and stands upon the matter. Although there are existing differences between the two research geographical settings, the destinations can be associated on the basis of significant similarities; firstly they are both traditionally established mass tourism destinations mainly relying on the sun and beach offers and, secondly they are both situated in the maturity phase of their respective lifecycles. The body of primary data is made out of 26 in-depth interviews realized throughout the summer of 2007. The comparison of the two different cases is commented on in an attempt to highlight the insights relative to the perceptions and feelings associated to climate change and tourism at local level.

Keywords: coastal tourism, climate change, discourse analysis, global and local scale, awareness.
\end{abstract}

\section{Introduction}

That the world climatic systems are going through a phase of change and that this change is being underpinned by anthropogenic activities appear to be supported by a wide array of scientific and physical evidence. The IPCC Fourth Assessment Report states that "warming of the climate system is unequivocal...evident from observations of increases in global average air and 
ocean temperatures, widespread melting of snow and ice and rising global average sea level" and "...Most of the observed increase in global average temperatures since the mid-20th century is very likely due to the observed increase in anthropogenic GHG concentrations". The report distinguishes the estimated consequences due to climatic change both on global and regional scales. According to the IPCC adaptation and mitigation are the suggested strategies to be followed by policymakers in order to slow down the increasingly faster pace of climatic change and minimize the associated estimated impacts [1].

It is undeniable that the numerous components of the tourism industry, in virtue of its global relevance, constitute a significant part of the anthropogenic activities that are deemed to be the source of the problem. Since the beginning of the $21^{\text {st }}$ century increasing concern has been gradually associated to the climate (change)-tourism issue [2-5]. In 2003 UNWTO organized the First International Conference on Climate Change and Tourism. In October 2007 the 2nd International Conference on Climate Change and Tourism, endorsed by UNWTO, UNEP and the World Meteorological Organization (WMO), was held in Davos. It reached the conclusion that "... (is urged) action by the entire tourism sector to face climate change as one of the greatest challenges..." [6].

In Europe the dominant tourist flow is currently represented by the mass of tourists that, from the northern and central countries, head each summer towards the Mediterranean coasts [7]. According to the available scenario forecasts for Europe, climate change should bring forth some common consequences for the continent but also trigger impacts that are locally determined depending on the geophysical characteristics. Increased risk of inland flash floods, more frequent coastal flooding, increased erosion and reduced water availability are expected to affect Europe as a whole; the associated consequences will vary, though, from region to region [1]. The Summary of the "Technical report on Climate Change and Tourism - Responding to the Global Challenge" prepared for the Davos conference detects four potential impacts on tourism associated with climate change: 1) direct climatic impacts, 2) indirect climatic impacts, 3) impacts due to societal change and 4) to the enforcement of mitigation policies. These consequences are expected to combine differently as a function of the characteristics of each tourist destination.

Central governments and tourism ministries will always have a key role to play in defining and promoting action to be taken by the tourism sector in response to climate change. However, it is likely that such initiatives will need to be implemented at a sub-regional or local level in order to take into account local conditions and needs [8]. This paper presents and discusses the results of two case studies addressed by the Msc thesis research projects of Mariska Both and Rodolfo Gaita, from the University of Wageningen. The research object has been, respectively, to investigate the translation of the global debate on tourism and climate change into the discourses of different categories of local tourist stakeholders (policymakers, private entrepreneurship and NGO) in Zandvoort (NL) and Axarquía (ES). The first step will be to introduce the research context and to specify the relevant methodological remarks. Consequently the findings emerged from research activities will be presented and commented. 


\section{Research context}

According to the Climate Change and Its Impacts on Tourism [9], the WTO Background Paper on Climate Change and Tourism [7] and to the latest Climate Change and Tourism Responding to Global Challenges [6] reports the areas interested by the tourist flow Northern Europe-Mediterranean are going to be subjected to dissimilar impacts. These are going to affect tourist offer and tourism demand in each area, in relation to both push and pull factors. In the Mediterranean areas increased health risks, occurrence of heath waves, pressure on water resources with possible droughts and coastal erosion might jeopardize the area's appeal for the Northern-European tourists. Moreover the estimated average temperature increase for Northern Europe could, under some aspects, improve the local climatic conditions, thus encouraging the tourist demand to "...adapt the travel patterns to take advantage of new climatic opportunities closer to home..." [6].

The case studies focus on two established coastal destinations visited mostly for beach \& sea purposes. The first is the tourist pole of Zandvoort, located in the Netherlands on the Northern Sea coast and the second one is the tourist pole of Eastern Costa del Sol, known as Axarquía and located in the Autonomic Region of Andalucía, on the southern Mediterranean coast. Zandvoort is visited by 4 million tourists each year, while Axarquía accounts for about half of the 9, 2 million arrivals registered in 2006 in the whole Costa del Sol. Although they developed in different periods, both destinations are currently in a phase of maturity of the respective life-cycles, characterized by a decreasing qualitative profile of the visitors. In the case of Zandvoort the negative affecting factors included the fear for UV-radiation, the external strong competition of established as well as new Mediterranean destinations and the internal competition of the increasing alternative offers of leisure and sport [10]. For Eastern Costa del Sol the adverse factors are represented by the rise of new tourist destinations competing for the sun and beach segment and the loss of environmental quality prompted by the rapid growth of urbanization rate and population density [11].

The estimated CC consequences on the short-medium term for Zandvoort are the increase of the average temperatures by something within the $0,5-1{ }^{\circ} \mathrm{C}$ and sea level rise by $15-25 \mathrm{~cm}$., causing reduced availability of fresh water, coastal erosion and flooding. In the case of Axarquía the expected impacts consist of rising average temperatures by $0,3-0,7^{\circ} \mathrm{C}$, sea level rising, increased vulnerability of the coastal environments, salt-water infiltration, increased pressure on fresh water resources and increased desertification. In both cases, though, it has not been possible to ascertain accurately what shall be the consequences of climate change, their magnitude and the pace at which they shall occur [12].

\subsection{Methodology}

Both research projects were characterized by a qualitative approach. The data of qualitative research are the text and the language through which the informants 
express their perceptions and views. Text is the outcome of the entire social, political and psychological condition of that individual [13]. The underlying assumption here is that language does not simply describe the world around us, but rather plays an important role in shaping it and its meaning. In this sense it can be said that language can construct reality [14].

In this instance the research object has been to explore if and how the global debate on climate change and tourism exists at local level, in the cases of two tourist destinations belonging to different geographical and cultural context nonetheless, under certain aspect, comparable.

\subsubsection{Data collection}

Both primary and secondary data have been employed. Secondary data are constituted by official reports, press releases and relevant scientific researches publications. Primary data consist of a total of 26 interview texts obtained by conducting semi structured, face to face, interviews with the sampled local stakeholders: 12 in Zandvoort and 14 in Axarquía. The informants included policymakers, entrepreneurs and members of environmental NGOs. The interview sampling had been originally designed to be purposive, following a snowball technique that would have eventually ended by reaching data saturation [13]. Due to a series of limits, which will be dealt in the paragraph 2.1.3, this sampling had to be adjusted and turned into a sampling of convenience.

\subsubsection{Data analysis}

The analysis of the research data relied on a textual analysis technique, due to the central role of text for this research. It was chosen to use a method inspired by the analysis of discourse, an analytical tool already employed to research a wide variety of issues, ranging from marketing to social and political implications of environmental issues such as acid rain [15] or the Ozone layer depletion. A discourse is a set of concepts that structure the contributions of participants to a discussion, and discourse analysis focuses on the way in which the social interaction evolves via the exchange of linguistic and symbolic utterances [15]. Every discourse is related to other discourses and can be best understood on the basis of their mutual relations, determined by the existing relations among the speakers.

Discourse analysis focuses on the way language is used, what it is used for and the social context in which it is used addressing aspects of communication beyond its content [13]. If a discourse clearly prevails over the competing discourses is defined as discourse structuration. The structuration of discourse turns into institutionalization when the discourse that has prevailed is adopted by official institutions that regulate social life through policy-making [15]. The recent debate on climate change will make the changes in weather patrons a more relevant issue for tourism stakeholders. With the (fragile) relation between tourism and climate at the back of our minds, it becomes interesting to investigate how the tourism sector perceives climate change and discourse analysis appears to be the most suitable tool for achieving it.

The discourse analysis employed in this research draws from the Argumentative Discourse Analysis, as described and employed by Hajer [15], 
but has been tailored to the contextual purposes and constraints. To minimize the risks of research invalidity the secondary data have been triangulated, as well as, consequently, secondary and primary data.

\subsubsection{Research limitations}

A few remarks are needed in order to give the right dimension to the research. First the relative novelty of this research methodology on this particular topic. It can be considered a pioneer study and a first step for further researches to come, thus its design and realization phases have margins of improvement. Secondly, the time and material resources available to the researchers and the fact that some of contacted potential informants denied their availability affected the planned research sampling. It has not been possible, in fact, to interview all the relevant stakeholders originally sampled after researching the pertinent documents. The research goal was, in essence, to make explicit some differences and similarities in the way the global discourse on climate change is implemented in local discourses as a starting point for further research.

\section{Local debates}

The scrutiny of the international debate on tourism and $\mathrm{CC}$ highlighted the existence of an institutional discourse based on the belief that climate change is happening now and its impact on tourism must be taken seriously. The two prevailing lines of actions for tourism industry appear to be mitigation on one hand and adaptation on the other. In this view the potential impacts of climate change have very important implications for employment, investment policies, governments' policies and for the livelihood of local residents. It therefore seems essential the involvement of tourism industry in joint initiatives (with governments, the research community, local authorities or international agencies) to assess the implications of climate change and act on the triggering causes.

\subsection{Zandvoort}

\subsubsection{Policymakers}

The international institutional discourse about climate change and tourism seems to be widely acknowledged and employed as reference at local level [16]. This has been the case for all interviewees except one, who expressed skepticism towards CC scientific explanations provided by the IPCC so far. There are essentially two discourses characterizing those informants that can be labeled institutional believers. For the group clustered around the first discourse the main concerns are represented by the threats posed by climate change to the current path of development, while the party adhering to the second is rather focused on finding the ways to benefit from future impacts. The implications are that one discourse associates more closely to mitigative strategies to prevent the change and the other to strategies that could allow adapting to and benefiting form the change. Such discussed measures contemplate, for example, widening the coastal defense, sand supplement of the coast, integrating climate proof parameters in architecture and increasing fresh water storage capacity. Within 
the institutional believers it is possible to draw a distinction between two main sub-groups.

\section{Weak Believers}

Although these informants are aware of the basic general knowledge regarding climate change, their conceptualization is mainly relying on information passed by mass media, thus resulting in being shaped by a huge amount of consistent and contradictory information. The clearness and accuracy of their understanding of the phenomenon is therefore affected. They declare to be in favor of taking every possible step, to begin with those that don't require big investment costs, to reduce emissions. More perplexities are expressed towards what adaptation measures should be taken and they way they should be financed. In this respect they look to the central administration in wait of more precise indications and concrete help to favor the implementation of the strategies that will be progressively defined.

\section{Strong Believers}

Strong believers not only are informed through the media, but also actively seek to keep themselves updated via specialized publications, the internet and scientific journals. They support the mitigation approach but appear more willing to actively pursue adaptive strategies. Nonetheless the constraints relative to resource and expertise availability at local level limit the scope of actions. Currently the actions that are given priority at local political level regard the improvement of public transportation encouraging the use of bikes and support the applications for eco-award such as Blue Flag and Green Key [10].

\subsubsection{Local entrepreneurs}

Also in this case is highlighted the central referential role of the institutional discourse, with two differences. The share of the declared skeptics is higher than within the policymakers and the weak believers' position resembles that of the skeptics. Skeptical and weak believers both are characterized by a wait and see approach: their are concerned with issues related to sustainability but are not willing to make any investments apart from those that will have a sound economic return. They expect the public administration to provide guidance and assistance on CC related issues. Strong believers are, on the contrary, investing their own resources for keeping updated with sustainable practices and technologies. Within the limits of their own possibilities these entrepreneurs took the effort to prepare an Environmental Plan to present to the Municipality and the other entrepreneurs.

\subsubsection{Environmental NGOs}

The NGO informants proved to belong to the strong believers' group. The scientific conclusions of the IPCC are accepted and agreed upon; nonetheless these interviewees actively search for information through other media and from other sources. Their discourse is that of climate change as national threat; critics are directed to the local administration, which is said to be leaning back and waiting for national policies, and to the national administrations, which is believed to be too narrowly focused on mitigation. Their main concerns are the 
consequences that beach erosion and sea level rise could have on the local human and natural systems.

\subsection{Axarquía}

\subsubsection{Policymakers}

Several Institutional documents like the PNA II 2008-2012 or the Impactos en la Costa Española por efecto del Cambio Climático testify how broadly accepted are the thesis of the IPCC and UNWTO at national political level. This picture has also been substantiated by the results yielded by the interviews conducted with local policymakers. Only one informant distinguished himself from the institutional believers by being admittedly a skeptic. The debate on CC and tourism is integrated within that of sustainability; urban planning, resources' use, energetic efficiency, waste generation and treatment are in fact the issues being investigated together with the potential impacts on the natural environments. Also in this case the range of possible actions to take is polarized around the concepts of mitigation and adaptation. The discourse of $\mathrm{CC}$ as a threat is dominant, and supported by the fact that potential risk of desertification, droughts, salt-water infiltrations, and coastal erosion could badly harm the local tourist industry. The discourse of $\mathrm{CC}$ as a new opportunity is, on the other hand, relying on the variation of tourist seasonality and on the faith in the resilience of the local tourist system. A distinction can be drawn, once more, between strong and weak believers.

\section{Weak Believers}

As for the Dutch case they don't question CC and its potential impacts on local tourism but their knowledge about the phenomenon is built on the information propagated by mass media. This fact contributes to the feeling of uncertainty they share about what will be the consequences, when they'll become evident and what can be done to limit the negative ones. They are, substantially, waiting for the central government to give clear indications about what has to be done, and how.

\section{Strong Believers}

More accurately informed, the strong believers are either performing autonomous researches about the issue or actively contributing to the debate locally. The steering role of the central governments is considered very important, but is also stressed the importance of the cooperation and contribution of each group of civil society. Mitigating and adaptive strategies are pursued with equal commitment, although the lack of local resources renders the coinvolvement of the central administration fundamental. The discussed mitigating measures are eco-efficiency, waste generation and recycling while the adaptive regard possibilities for water storage, land use management and new parameters to be integrated into architecture.

Two are the current political priorities associated to the debate on sustainability, tourism and $\mathrm{CC}$ : facilitating on the one hand the tourist entrepreneurs' application processes to be awarded one or more ecocertifications while, on the other, reforming the processes of urban planning and 
land management, in consideration of some problems that have already occurred, which could increase local vulnerability to $\mathrm{CC}$ and its negative impacts.

\subsubsection{Local entrepreneurs}

Tourist entrepreneurs constitute a uniform group of weak believers. They all know about CC and related potential impacts; some even asserted having directly witnessed them. It has not been possible to discern the existence of either a threat or opportunity discourse within this group, most probably because of the early stage of the debate and because of the different time span employed for the study of CC and for planning tourist development. They appear to be willing to take action but wait for the central and local administration to provide guidelines and support. The current priorities for local entrepreneurship are the integration of sustainable practices into tourist activities, the development of more varied attractions, decrease of seasonality and the improvement of the qualitative profile of the visitors.

\subsubsection{Environmental NGOs}

The interviewed environmentalists see CC debate as an opportunity that can favor the integration of sustainable principles within human activities such as tourism, which is dominant at local level. They all belong to the group of active believers and their main discourse is definitively that of $\mathrm{CC}$ as a threat. The current tourist development, associated with a model of residential tourism relying on the progressive creation of new urbanizations is also perceived as a major threat. Climate Change is indeed believed to be the other big threat Spain has to face together with the problem of uncontrolled urbanization. The latter, in fact, would affect various environmental aspects thus increasing vulnerability to $\mathrm{CC}$ estimated impacts like increased pressure on water resources, waste generation, coastal erosion, saltwater infiltration and biodiversity loss. Local environmentalists' main activities are the organization of awareness-raising campaigns, pressuring the policymakers for updating environmental policies and monitoring the respect of the existent environmental regulations.

\section{Conclusions}

Both cases show that the global institutional discourse constitutes the reference point for the local debates in Zandvoort and Axarquía. In the case of Zandvoort, though, the perceptions of $\mathrm{CC}$ as a threat are balanced by those of $\mathrm{CC}$ as on opportunity, while for in the case of Axarquía is generally perceived as a threat.

Although the global discourse and the national plans emphasize both mitigations and adaptation options the current actions are mainly associated with mitigating measures. The relative uncertainty characterizing the phenomenon, coupled with the sensationalist approach of the media might determine that the quantification of the required costs for adaptive measures prevail over the vague estimates of the impacts. Among the local policymakers and tourist entrepreneurs there's the tendency to delegate the responsibility for defining and 
taking due actions to the national administrations, justified by the limited availability of resource and expertise at local level. In Axarquía the debate on Tourism and CC intermingles with that related more broadly to sustainability, because of environmental and social problems that emerged as consequences of the tourist development model. In this respect it seemed that the environmental and economical agencies of the administration are just about to reach a common ground of cooperation.

The tourist entrepreneurs are getting more and more involved in the processes to obtain eco-certifications. It can be interpreted as a first step towards the integration of sustainability within business practices and, thus, a way to decrease local vulnerability to CC. Nonetheless they haven't yet addressed the issue and the specific implications it would prompt for their businesses. This is consistent with what Hall has observed in New Zealand. Although there is widespread concern about climate change, it is of secondary importance in comparison to other issues in people's daily lives [5].

\section{Discussion}

The two research projects brought to surface that the local translation of global tourism-CC debate just got started and is still characterized by uncertainties. For example some informants even believe having already witnessed some of the associated consequences, nonetheless this fact hadn't significantly changed or affected the way they were living their lives or conducting their business. In order to put the guidelines and objectives stated in the institutional documents and reports into practice there is, in both cases, the manifest need to take two actions. First to improve the coordination among the institutional and research actors, and second to explore other ways to stimulate the debate and the involvement of society at large. New ways could be, for example, debates, information evenings and informal drinks about the subject.

The two research projects also showed that discourse analysis can be a fruitful approach through which investigate the translation of the global debate on tourism and climate change into the discourses of different categories of local tourist stakeholders (policymakers, private entrepreneurship and NGO). However, these two research projects were preliminary attempts to do so and had their limitations. I suggest to continue this path of enquire by conducting more in-depth research on individual case studies, longitudinal research over time of the same case studies and, finally, more comparative research including other case studies in other parts of Europe.

\section{Acknowledgements}

Grateful thanks go to each research informant, for their availability and disposition, and to Martijn Duineveld and Dr. V.R. (René) van der Duim (Sociospatial Analysis chair-group, Wageningen University) for their invaluable guidance and support during the research process. 


\section{References}

[1] International Panel on Climate Change-http://www.ipcc.ch/pdf/assessmentreport/ar4/syr/ar4_syr_spm.pdf

[2] Hamilton J.M. et al. (2003) Climate change and international tourism: A simulation study. Working Paper FNU-31, Research Unit Sustainability and Global Change, University of Hamburg.

[3] Gómez Martín, M.B., Reflexión Geográfica en torno al Binomio ClimaTurismo. Boletín de la A.G.E. 40, pp. 111-134, 2005.

[4] Amelung, B. and Viner, D., Mediterranean Tourism: Exploring the Future with the Tourism Climate Index. Journal of Sustainable Tourism 14 (4), pp. 349-366, 2006.

[5] Hall, C.M., New Zealand Tourism entrepreneur attitudes and behaviours with respect to climate change adaptation and mitigation. Innovation and Sustainable Development, 1 (3), pp. 229-237, 2006.

[6] UN World Tourism Organization-http://www.unwto.org/climate/index.php

[7] Todd, G., WTO Background Paper on Climate Change and Tourism. Proc. of the First International Conference on Climate Change and Tourism, UNWTO: Djerba, Tunisia, pp. 11-15, 2003.

[8] Mather, S., Viner, D. \& Todd, G., Climate and policy changes: their implication for international tourism flows. Aspects of Tourism: Tourism, Recreation and Climate Change. ed. C.M. Hall \& J.E.S. Ingham, Channel View Publication: Clevedon, pp. 63-86, 2005.

[9] WWF U.K.-http://www.wwf.org.uk/core/index.asp

[10] Milieubeleidsplan gemeente Zandvoort, periode 2007 - 2011. Gemeente Zandvoort, Milieudienst IJmond, Beverwijk, 2007.

[11] Impactos en la Costa Española por efecto del Cambio Climatico$\mathrm{http}: / /$ www.mma.es/portal/secciones/cambio_climatico/

[12] Plan Nacional de Adaptación al Cambio Climáticohttp://www.mma.es/portal/secciones/cambio_climatico/areas_tematicas/im pactos_cc/pnacc.htm

[13] Punch, K. F., Introduction to Social Research. Sage Publications: London, 2005.

[14] Willing, C., Applied discourse analysis, social and psychological interventions. Open University Press: Buckingham, 1999.

[15] Hajer, M., Coalitions, practices and meanings in environmental politics: From Acid Rain to BSE. Discourse Analysis and European Politics. ed. J. Torfing, Palgrave: London, pp. 297-315, 2004.

[16] The effects of climate change in the Netherlands. Netherlands Environmental Assessment Agency, MNP, Bilthoven, 2005. 